Superintendência de Controle de Endemias (Sucen), Secretaria de Estado da Saúde de São Paulo (SES)
Correspondência | Correspondence: Secretaria de Estado da Saúde de São Paulo Av. Dr. Arnaldo, $3511^{\circ}$ andar sala 135 01246-901 São Paulo, SP, Brasil? E-mail: agencia@saude.sp.gov.br

Texto de difusão técnico-científica da Secretaria de Estado da Saúde de São Paulo.

\section{Manejo integrado para prevenção da proliferação de vetores de dengue $e$ leishmaniose e de escorpiões}

\author{
Integrated management for the \\ prevention of proliferation of dengue \\ and leishmaniosis vectors and \\ scorpions
}

\section{PROPOSTA}

O processo de trabalho em saúde inclui uma multiplicidade de ações, que visam atender as necessidades percebidas ou sentidas pelos grupos sociais, e também aquelas que os profissionais de saúde identificam como prioritárias no contexto epidemiológico local, para as quais propõem intervenções específicas.

A Portaria 1172 do Ministério da Saúde define as competências das três esferas de governo no desenvolvimento das ações de vigilância em saúde, cabe ao Estado a coordenação e acompanhamento das ações executadas pelos municípios. Neste contexto, o Serviço Regional da Superintendência de Controle de Endemias (Sucen) de Presidente Prudente elaborou proposta de ampliação das ações de vigilância e controle vetorial, enfatizando a promoção à saúde e a identificação de fatores de risco para o estabelecimento da transmissão da leishmaniose visceral americana (LVA) humana e da dengue e a proliferação de escorpiões. Tratando-se de problemas relacionados ao meio ambiente das áreas urbanas dos municípios, exigem intervenção da população local para um saneamento domiciliar adequado, contribuindo para a melhoria da qualidade de vida.

A proposta teve como objetivo racionalizar as atividades desenvolvidas e se constituiu numa reorganização do processo de trabalho em controle de vetores. Para tanto, levou-se em conta a análise dos problemas e a compreensão das necessidades de saúde dos diversos grupos da população, com ampliação da discussão para a transformação das práticas enfatizando o território local. Primeiramente, foi realizado um levantamento das condições sanitárias dos domicílios relacionados com vetores de dengue e LVA, e de escorpiões. Com base neste levantamento, os agentes de controle de vetores orientaram a população para a prática de ações de manejo ambiental e de controle mecânico integradas. Tais medidas visavam a promoção de saúde e prevenção de riscos ambientais, por meio do planejamento, organização, realização e monitoramento de atividades para a manipulação e/ou modificação de fatores ambientais ou a sua interação com o homem. Assim, a propagação de vetores pode ser prevenida ou minimizada, ou o contato homem-vetor-patógeno, diminuído.

Um indicador entomológico fornece informações valiosas para o direcionamento das atividades de controle do vetor da dengue, a exemplo dos recipientes existentes, isto é, aqueles com condições de acumular água. O indicador é obtido por meio de um levantamento por amostragem de conglomerados, quarteirões, realizado pelos municípios com periodicidade trimestral, onde são pesquisadas, no mínimo, 300 edificações. Nesse levantamento também são obtidas informações sobre os recipientes pesquisados e aqueles com larvas de Aedes aegypti. Os recipientes mais freqüentemente encontrados são vasos e pratos de plantas. Há também os inservíveis (latas, potes e frascos, garrafas) e aqueles não removíveis (piscinas, bebedouros de animais, lonas) e outros de utilidade para o morador. Pneus e caixas d'água apresentaram maiores percentuais de positividade para Ae. aegypti em relação aos outros tipos.

A Leishmaniose Visceral Americana (LVA) é uma infecção zoonótica que afeta animais e o homem. No Estado de São Paulo, vem se verificando um processo de expansão da doença, uma vez que o principal vetor, Lutzomyia longipalpis, se adapta ao ambiente doméstico. Nesses ambientes há oferta de resíduos sólidos orgânicos em locais com umidade e sombreamento, e disponibilidade de fonte de alimentação, 
principalmente a canina. Considerada como a principal fonte de infecção, a população canina é abundante na região.

A análise da situação entomológica e epidemiológica permitiu classificar as Regiões do Estado em vulneráveis, com transmissão, em investigação e aquelas receptivas, onde já foi detectado o vetor. O programa de controle da LVA contempla ações de vigilância epidemiológica - baseadas na detecção e tratamento oportuno dos casos humanos -; vigilância entomológica e controle vetorial; e controle da população canina infectada. $O$ controle vetorial vem sendo implementado por meio de atividades de saneamento ambiental, que visam reduzir os locais prováveis de criação do vetor, ou do seu repouso. Estas ações estão embasadas no manejo do ambiente por meio da retirada de matéria orgânica em decomposição no peridomicílio, poda de galhos e arbustos.

Na perspectiva de prevenção da ocorrência de LVA, foram desenvolvidas ações de vigilância entomológica na Região de Presidente Prudente, SP, em municípios vulneráveis, ou seja, aqueles com possibilidade de introdução da fonte de infecção. Essas ações resultaram no encontro de Lu. longipalpis em 12 deles, tendo sido constatada a ocorrência de transmissão canina em dois deles e da canina e humana em dois.

Quanto aos escorpiões, em todos os municípios foi detectada a presença da espécie de Tityus serrulatus, aracnídeo que provoca acidentes graves, tendo uma média de 50 notificações/ano.

\section{DESCRIÇÃO E RESULTADOS PRELIMINARES}

A Região de Presidente Prudente possui uma população total de 682.823 habitantes em 45 municípios, dos quais $75 \%$ destes, inferior a 20.000 habitantes. Na primeira etapa, foi iniciado o planejamento para operacionalizar a proposta em conjunto com a equipe gerencial municipal e definir a programação das ações considerando a delimitação do problema, capacidade de acompanhamento, recursos necessários para enfrentá-los e analisar a forma de comunicação social para mobilização da comunidade com vistas a sua incorporação ao processo de execução das práticas de promoção.

$\mathrm{Na}$ etapa inicial do trabalho foram envolvidas as lideranças municipais de oito municípios; Vigilância Epidemiológica, Vigilância Sanitária, Secretaria de Obras, Conselho Municipal de Saúde, Controle de Vetores e Veterinários. Os profissionais destas áreas realizaram o diagnóstico da situação de LVA e dengue e de acidentes por escorpião. Foi realizada uma avaliação dos indicadores entomológicos disponíveis com base na bioecologia dos vetores. Também foi discutida a posse responsável de animais domésticos, resultando na elaboração da proposta de visita domiciliar integrada com ênfase no manejo ambiental. Essa proposta está de acordo com as normas estabelecidas pelas diretrizes técnicas adotadas no Estado de São Paulo.

A etapa seguinte consistiu da capacitação dos supervisores e do profissional de Informação, Educação e Comunicação e das equipes de campo dos municípios e da Sucen para a realização das atividades. Essas informações permitiram realizar: a classificação dos locais com probabilidade de servirem de criadouros para $L u$. longipalpis e de fontes de alimentação; a identificação de criadouros de Ae. aegypti e de locais propícios para o encontro de escorpião.

Foi utilizado um roteiro* durante as visitas domiciliares para classificação dos imóveis segundo níveis de risco para ocorrência dos vetores de dengue, LVA e de escorpião. Em conjunto com os municípios, elaborou-se um Protocolo de Orientação, * utilizado para estabelecer prazo para implementação das recomendações e agendamento de retorno para nova avaliação, para os moradores dos imóveis com risco.

A visita de retorno foi realizada dez a 30 dias após, pelo mesmo agente que procedeu a primeira classificação do imóvel. Em situações de resistência por parte do morador, ou quando do encontro de situações complexas, foi acionada a Vigilância Sanitária municipal, que em alguns municípios, teve papel importante para o incremento das medidas cabíveis.

Foram visitados 48.155 imóveis para o diagnóstico inicial e preenchidos $2.852(5,9 \%)$ protocolos em imóveis críticos, com apresentação das recomendações aos moradores (Tabela 1).

De maneira geral, não foi observada diminuição da cobertura nas atividades de vigilância de Ae. aegypti com a incorporação das outras ações integradas nesses municípios. A cobertura média foi de $84,7 \%$, com produção diária de 20 a 28,5 visitas, enquanto o rendimento médio para as visitas de rotina para dengue é de 25 a 30 imóveis por dia. Este resultado deve-se, por um lado, à suplementação do trabalho por servidores do Estado em alguns municípios. Por outro lado, devese à folga operacional constatada em municípios de pequeno e médio porte, que têm condições de cobrir a periodicidade das pesquisas casa a casa com número reduzido de agentes.

\section{PROTOCOLO DE RECOMENDAÇÃO}

O protocolo de recomendação aos moradores contemplou no mínimo 22 sugestões, incorporadas de acordo 
Tabela 1. Número de imóveis trabalhados e de protocolos. Região de Presidente Prudente, SP, 2004.

\begin{tabular}{lccc}
\hline Município & População & $\begin{array}{c}\text { Imóveis } \\
\text { trabalhados }\end{array}$ & $\begin{array}{c}\text { Protocolos } \\
\text { preenchidos }\end{array}$ \\
\hline Martinópolis & 22.344 & 6.831 & 730 \\
Monte Castelo & 4.089 & 1.275 & 92 \\
$\begin{array}{l}\text { Presidente Epi- } \\
\text { tácio }\end{array}$ & 39.274 & 1.099 & 212 \\
Rancharia & 28.776 & 9.544 & 357 \\
$\begin{array}{l}\text { Tupi Paulista } \\
\text { Nova Guatapo- }\end{array}$ & 13.289 & 4.654 & 352 \\
ranga & 2.087 & 280 & 57 \\
Dracena & 40.479 & 22.129 & 956 \\
Ouro Verde & 7.146 & 2.343 & 96 \\
\hline Total & & 48.155 & 2.852 \\
\hline
\end{tabular}

com a realidade de cada município e discussão prévia com a Secretaria Municipal de Saúde. Maior dificuldade foi observada na implementação daquelas relacionadas às fontes de alimentação do vetor da leishmaniose visceral, e presença de animais em área urbana (galinha, porco, entre outros). Dificuldades também foram encontradas na retirada de matéria orgânica dos quintais e para o destino de cães errantes, uma vez que, à exceção do município de Dracena, não existia canil ou centro de controle de zoonoses nessa região. As recomendações efetivamente realizadas foram assim distribuídas: $56,4 \%$ para as ações de manejo, principalmente aquelas relacionadas com eliminação de matéria orgânica em decomposição, como folhas, frutos e fezes em locais prováveis de procriação do Lu. longipalpis; $27,9 \%$ para locais de abrigo para escorpião, como madeiras e tijolos e $13,1 \%$ para controle mecânico dos criadouros do $A e$. aegypti, na sua maioria para retirada de inservíveis dos quintais.

Para os cinco municípios que realizaram o cotejo da classificação de risco de imóveis (Martinópolis, Presidente Epitácio, Monte Castelo, Tupi Paulista e Rancharia), antes e após a adoção das medidas recomendadas, verificou-se diferença significativa da classificação entre a primeira e segunda visita. Tal cálculo foi pelo teste de Wilcoxon para dados pareados, utilizando-se o pacote estatístico SPSS 11. Os dados foram analisados conjuntamente e organizados em tabelas. As hipóteses foram testadas ao nível de significância de 5\%, e concluiu-se que as mudanças ocorridas nas classificações para os riscos alto, médio e baixo na segunda visita foram estatisticamente significativas em todos os municípios.

As Tabelas 2 a 4 apontam que do total de classificação dos riscos para Ae aegypti, escorpião e Lu. longipalpis, da primeira visita em relação à segunda visita, houve redução da categoria alta e média e aumento dos imóveis classificados como baixo e sem risco.

Quanto à classificação de risco alto para as três situações, o vetor da dengue foi o menos contemplado, devido já ser uma endemia trabalhada pelos agentes municipais no decorrer dos anos.

Observou-se que houve um aumento dos imóveis sem risco para a ocorrência de Ae. aegypti de 843 na primeira visita para 1.320 na segunda, assim como a diminuição do número de imóveis com alto, médio e baixo risco (Tabela 2 ).

Da mesma forma, houve aumento dos imóveis sem risco para ocorrência de escorpiões, de 288 na primeira visita para 1.058 na segunda, assim como a diminuição do número de imóveis com alto e médio risco (Tabela 3).

Também foi constatada queda acentuada do risco do número de imóveis com ocorrência de Lu. longipalpis, com maior destaque para aqueles com alto risco, de 466 para 22 e médio risco, de 902 para 78 (Tabela 4).

Os resultados obtidos apontam que essa proposta de atividade integrada durante a visita domiciliar é factível, apoiada por um protocolo de orientação aos moradores de imóveis mais críticos. Houve boa resolução a partir das recomendações estabelecidas, em municípios de pequeno e médio porte, que se constituem na maioria daqueles localizados na Região trabalhada.

A classificação dos imóveis para o risco de ocorrência de doenças ou acidentes exige um esforço do trabalhador em saúde para interpretar as situações observadas,

Tabela 2. Classificação do risco de ocorrência de Aedes aegypti encontrado na segunda visita em relação à primeira visita realizada. Região de Presidente Prudente, SP, 2004.

\begin{tabular}{|c|c|c|c|c|c|c|c|c|c|}
\hline \multirow{2}{*}{$\begin{array}{l}\text { Classificação } \\
1^{\text {a }} \text { visita }\end{array}$} & \multirow[b]{2}{*}{ Alta } & \multirow[b]{2}{*}{$\%$} & \multirow[b]{2}{*}{ Média } & \multicolumn{2}{|c|}{$2^{\mathrm{a}}$ visita } & \multirow[b]{2}{*}{$\%$} & \multirow[b]{2}{*}{ Sem risco } & \multirow[b]{2}{*}{$\%$} & \multirow[b]{2}{*}{ Total $1^{\mathrm{a}}$ visita } \\
\hline & & & & $\%$ & Baixa & & & & \\
\hline Alta & 13 & 12,74 & 7 & 6,86 & 40 & 39,22 & 42 & 41,18 & 102 \\
\hline Média & 0 & & 14 & 4,83 & 131 & 45,17 & 145 & 50 & 290 \\
\hline Baixa & 0 & & 1 & 0,21 & 157 & 33,19 & 315 & 66,6 & 473 \\
\hline Sem risco & 0 & & 0 & & 25 & 2,97 & 818 & 97,03 & 843 \\
\hline Total $2^{\mathrm{a}}$ visita & 13 & & 22 & & 353 & & 1.320 & & 1.708 \\
\hline
\end{tabular}


Tabela 3. Classificação do risco de ocorrência de escorpião encontrado na segunda visita em relação à primeira visita realizada. Região de Presidente Prudente, SP, 2004

\begin{tabular}{|c|c|c|c|c|c|c|c|c|c|}
\hline \multirow{2}{*}{$\begin{array}{l}\text { Classificação } \\
1^{\text {a }} \text { visita }\end{array}$} & \multirow[b]{2}{*}{ Alta } & \multirow[b]{2}{*}{$\%$} & \multicolumn{3}{|c|}{$2^{\mathrm{a}}$ visita } & \multirow[b]{2}{*}{$\%$} & \multirow[b]{2}{*}{ Sem risco } & \multirow[b]{2}{*}{$\%$} & \multirow[b]{2}{*}{ Total $1^{\mathrm{a}}$ visita } \\
\hline & & & Média & $\%$ & Baixa & & & & \\
\hline Alta & 18 & 4,3 & 57 & 13,6 & 120 & 28,64 & 224 & 53,46 & 419 \\
\hline Média & & & 48 & 5,78 & 343 & 41,27 & 440 & 52,95 & 831 \\
\hline Baixa & & & 1 & 0,59 & 55 & 32,35 & 114 & 67,06 & 170 \\
\hline Sem risco & & & & & 8 & 2,78 & 280 & 97,22 & 288 \\
\hline Total $2^{\mathrm{a}}$ visita & 18 & & 106 & & 526 & & 1.058 & & 1.708 \\
\hline
\end{tabular}

Tabela 4. Classificação do risco de ocorrência de Lu. longipalpis encontrado na segunda visita em relação à primeira visita realizada. Região de Presidente Prudente, SP, 2004.

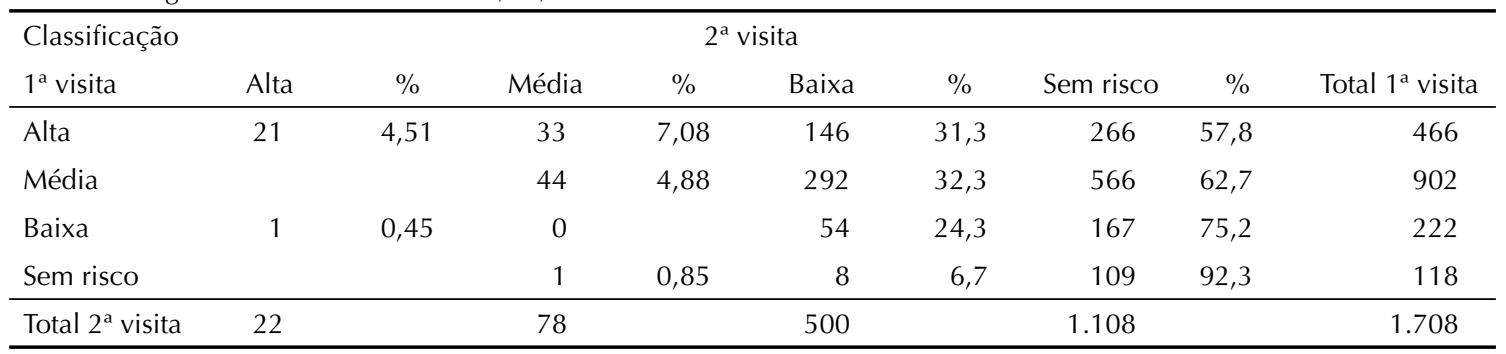

e, a partir daí, elaborar a proposta de intervenção e direcionamento. Esse esforço é acentuado pelo enfrentamento de muitos problemas que requerem ações de diferentes setores da administração municipal para serem resolvidos.

\section{IMPLEMENTAÇÃO DAS ATIVIDADES}

Dois aspectos importantes na implementação dessas atividades merecem ser destacados: em primeiro lugar, é necessário existir o compromisso das lideranças municipais em todo o processo, desde a organização da coleta dos resíduos resultantes do manejo ambiental até a resolução de problemas em terrenos baldios e casas desabitadas. $\mathrm{O}$ envolvimento de profissionais da Secretaria Municipal de Saúde, com destaque para o veterinário na triagem de cães suspeitos de LVA e do responsável pelas atividades educativas, na conscientização dos moradores para incorporação de ações sustentáveis de manejo dos locais de risco de proliferação de vetores e animais nocivos, levam à organização dos espaços domiciliares com melhor qualidade de vida.

O segundo aspecto foi incrementar o papel do Estado na assessoria e avaliação das ações, por meio da Sucen. Dessa forma, contribui para a implementação de políticas públicas frente à situação epidemiológica das doenças de transmissão vetorial e do controle de animais nocivos.

Também não é demasiado acrescentar a necessidade de ampliar o olhar do profissional, principalmente para as ações educativas, comunicativas e de gerenciamento. É preciso entender a importância do entrelaçamento das atividades desenvolvidas no espaço do próprio município e respeitar sua realidade e estrutura para garantia da integralidade da prática de saúde. 